\title{
AN INSIGHT OF NATURE INFLUENCES AND ENVIRONMENTAL SANDY ON ARCHITECTURE BY INFORMATION TECHNOLOGY
}

\author{
${ }^{1}$ Tim CHEN, ${ }^{2}$ Aeyed Mohammad HASHEMII \\ ${ }^{3}$ Rehaap Abd Elfatah NUSSIR, ${ }^{4}$ Ghanshyama PATANKAW \\ ${ }^{5}$ John C. Y. CHEN"
${ }^{1}$ Faculty of Information Technology, Ton Duc Thang University, Ho Chi Minh City, Vietnam e-mail: timchen@tdtu.edu.vn
${ }^{2,5}$ Department of Math and Mech, University Skii 28, St Petersburg 198504, Russia e-mail: jc343965@gmail.com
${ }^{3}$ Department of Geography, Karnataka University, India, e-mail: patanaw555@ku.in ${ }^{4}$ Department of Interior Applied Arts, 6 October University, e-mail: ririshreaif@yahoo.com
${ }_{5}^{5}$ Department of Computer Science and Engineering BRAC University 66 Mohakhali Dhaka 1212, Bangladesh, e-mail: jc343965@gmail.com

Received 27 August 2018; accepted 9 January 2019

\begin{abstract}
Environmental sandy construction is seeking about innovation, uniqueness substantive, symmetrical and congeniality with the scene. It applies zero-time substances (earth, water, air, and fire) in addition to the advantage of modernized technologies (smart and digital architecture) and re-revives the old models of conventional architectural techniques (contracts, domes). In order to find unorthodox solutions to interior configuration problems especially after physical disasters, the study highlights that it is remarkably critical to developing new intelligent solutions and atypical to the quandaries and requirements of interior design furniture by the concept of phenomenology, place, environment, and architecture.
\end{abstract}

Keywords: Environment, Technology, Interior design, Sandy, Architecture

\section{Introduction}

The comprehensive rural areas, which comprise traditional, aesthetic, cultural heritage and essential resources districts are the origin concerning the establishment of a country and its foundation [1], [2], [3]. Environmental sandy construction adapts across environmental gradients [4], [5], [6]. Architectural and design creativity is characterized by seeking about originality, uniqueness substantive, formal and compatibility with the environment, which led to the emergence of new environmental cycle and its applied in the (Environmental sandy architecture). In order to achieve integration with everything that surrounds them and interact with responsive to environmental, humanitarian and

${ }^{*}$ Corresponding Author 
design requirements reliance on zero-time materials (earth, water, air and fire) in addition to the use of state-of-art technologies and re-revive the old models of traditional architectural techniques (contracts, domes, inner courtyard). In order to find a relationship between it and the smart architecture and digital architecture, which seek to find unconventional solutions to interior design problems, study some of the various details of the sand construction techniques, how to use them in producing an internal designs integrated internally and externally, studied some pioneers of environmental architecture sand, study the feasibility of applying environmental architecture sand technique in Egypt, where was concluded that sand environmental architecture is one of the most important methods of energy and water conservation, as well as it implements a solution to the reconstruction after natural disasters, where it is necessary and extremely urgent to develop new rational solutions and atypical to the predicament and requirements of interior design furniture.

\section{The importance of search}

The study of the latest design theories and smart technology in environmental sandy architecture seeks to find unconventional solutions to the different problems of interior design.

- The development of new and rational solutions to the problems of a typical and the list of needs by seeking about originality and uniqueness substantive and formal with consistency and compatibility with the environmental surroundings;

- Monitor the most important contemporary architectural trends and thought architect who founded and which affected on designing of interior design.

No doubt that there are negative effects of the modern environment of buildings, for intense, depletion of resources, in the style of energy and water consumption, as well as in the production of waste and the bad health effects on the users of these buildings especially as a group they intimidate the continuity and the sustainability of civilized settlements. This prompted many professionals in the field of the environment and in the field of interior and architectural design to call for new ideas and design methods that value the environment and respects the right of future generations to a decent healthy life, and as a result of this integration between the environment and design environmental architecture emerged from ancient times and has changed their productions from one area to another. The objective of the construction is adjudicating to accommodate to the surrounding environment just because the man protects himself (examples: I. Eskimos architecture, for the prevention of snow, Fig. 1; II. Architecture mud villages of Egypt and Nubia (sandy), Fig. 2).

It is noted that each style expresses the extent adapted to its surroundings and architectural configuration is the largest crossing for the personal environment. The study sums up the definition of environmental architecture at some points:

1) Built environment that has functional efficiency, safety, health and comfort features;

2) Architecture that does not destroy the vital systems. 
Architecture that keeps the recoverable resources of the entry into force of the ground, and given the importance of the link between architecture and the environment (environmental architecture) appeared terms of new science confirms this link and study it carefully, as 'Architecture sandy environmental'.
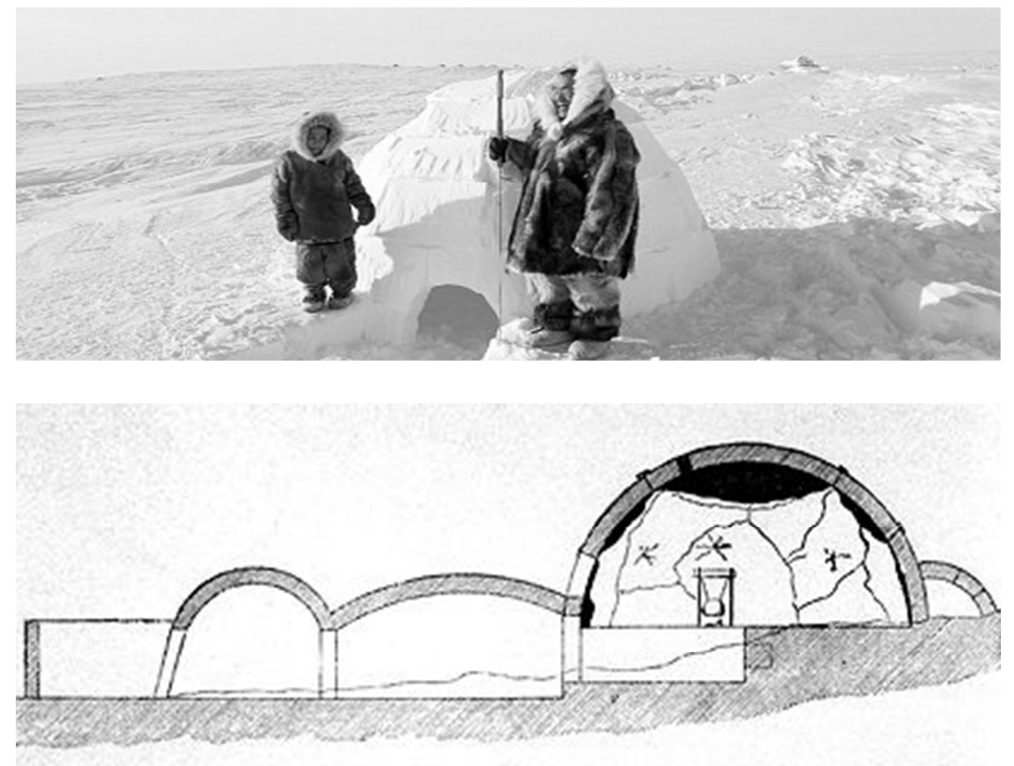

Fig. 1. Houses Eskimos who relied only on ice cubes to reach a steadfast determination in the face of solid low temperatures

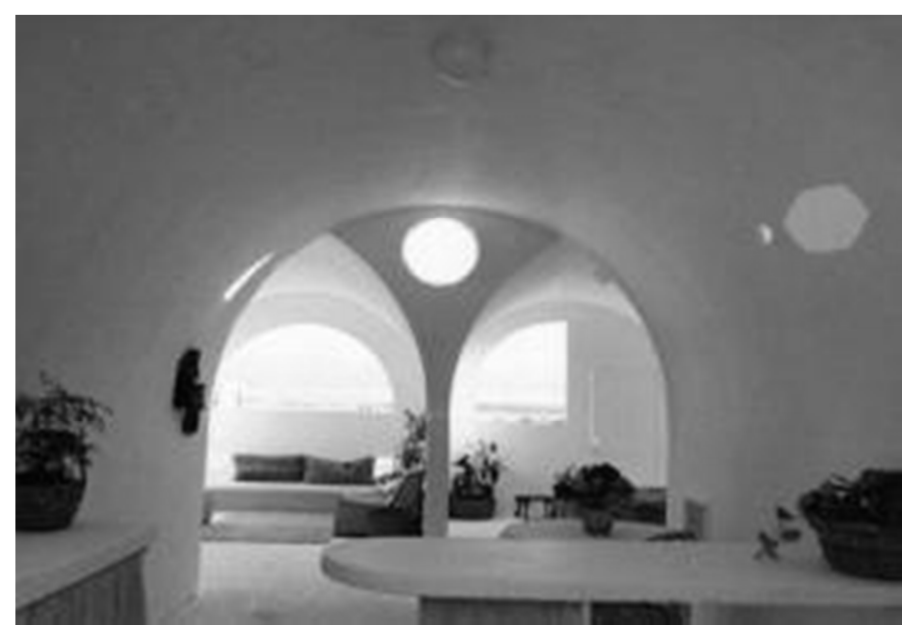

Fig. 2. Internal vacuum for one of the places in a manner based clay architecture 


\section{Environmental sandy architecture}

Creative product architect - popularly mother or officially - adopts a line intellectually, individually or collectively developed an innovative linked in the physical phase analysis of functionalism and structural implications and possibilities through scientific and cultural determinants and traditional fixed and variable. This line intellectual achieves his goals as fit by the recipient responds to the cultural needs of internal and external spaces. The technical product sends technical and emotional feelings to a function of a business.

These goals and solutions determined by the creator. And he responds to the uniqueness of the activities, behavioral patterns, custom, ceremonies, and traditions of individuals.

In this creative process devise new rational solutions and atypical problems of the list of needs. And talented artist achieves fun aesthetic and emotional formality of the blocks and new spaces and are aligned with the environment. The results of creativity of design depend on three components are:

- first: the physical creativity (vocational);

- second: artistic creativity - the talent of creative and artistic fun for the recipient;

- third: intellectual creativity - product innovation - creative thought - an intellectual pleasure to the recipient.

Disadvantages of using technology based 'environmental sandy architecture' on two main elements:

- Cost: in developed countries, high due to lack of manpower and this leads to higher construction costs; in developing countries, in this way the building is already dirt cheap in terms of labor and sometimes the occupants of the place ever built for themselves in the future and this is the proposal are available for possible floods, which adversely affected by the phenomenon in Egypt;

- Safety: theft and vandalism are two problems (can be solved by the use of smart technology) techniques of 'environmental sandy architecture' in the internal and external spaces. Aftermath how to avoid construction sand technical flaws to gain access to the internal vacuum environment integrated design techniques 'environmental sandy architecture' will be discussed in the next lines.

\section{The idea of design}

There are several techniques for building sand, all characterized by the same technique, and some of the most common ways with its advantages and disadvantages.

\subsection{Adobe mud}

This is the more traditional images of the construction of Turabi in the United States, where dating back to several thousand years, as has been used for many hundreds of years before the Spanish settlers. As for the world, it could be this 
technique has been used for more than ten thousand years old, were also present in all places in the early civilizations in Asia and Africa. The condition is indicated in Fig. 3.

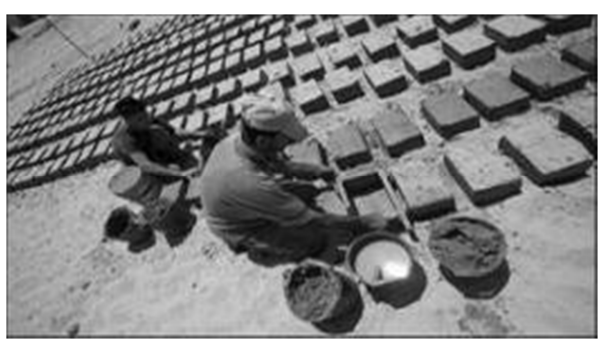

Fig. 3. Sand, water is the raw material to build a house in a way sandstone adobe

\subsection{Hollow brick compact mechanically compressed earth block}

This method differs from the method of 'adobe' where this method is used to mix the dry piston brick components called piston Sinfa Cinva ram, (cheap and therefore can be of any building is having an expert) and reduce the size of the compression process dust and rearranges the sand particles to form more stable block of material. The condition is indicated in Fig. 4.

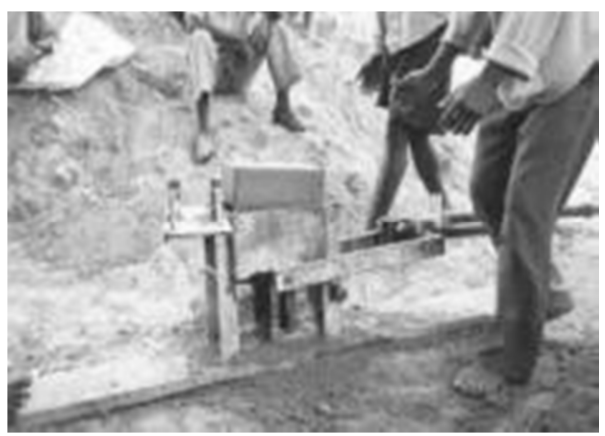

Fig. 4. The piston Sinfa used in mixing the components

\subsection{The cup of sand $\mathrm{Cob}$}

This Altaatguenih proceeded made from the former sand and brick explained, have parallels in all areas where the former is commonly used bricks. But it has traditionally been used in the British Isles site, hence derives its name and construction in a 'cup Cob' is an almost continuous process of ore processing operations and building walls. The condition is indicated in Fig. 5 and Fig. 6.

\subsection{The sand pressed rammed Earth}

This technique is the favorite for a long time as a way to build a multi-storey houses. It seems that China and France have the best traditions of building known for this style. 
Construction process, as it can be seen in Fig. 7, are compressed earth through the work of a wooden or metal molds for walls and filled with a mixture of soil and cement are stable pressure from tapping using hand tools or through the use of a mechanical device stressful.

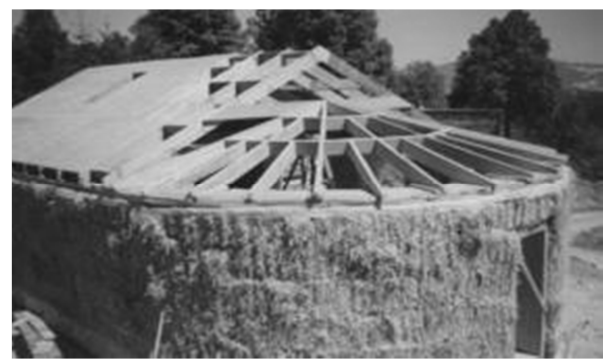

Fig. 5. Describes a method for the installation of ceil

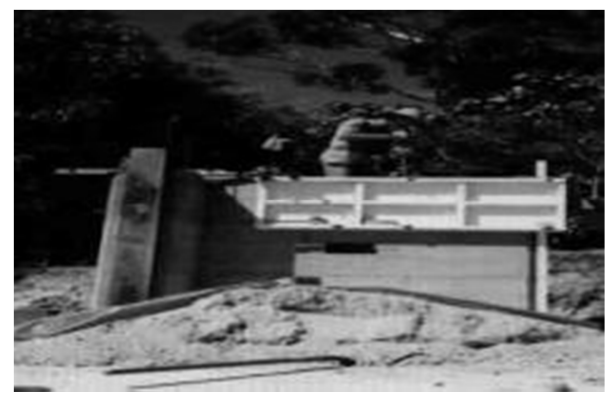

Fig. 6. Interest in interior design and the introduction of all fixtures in the design

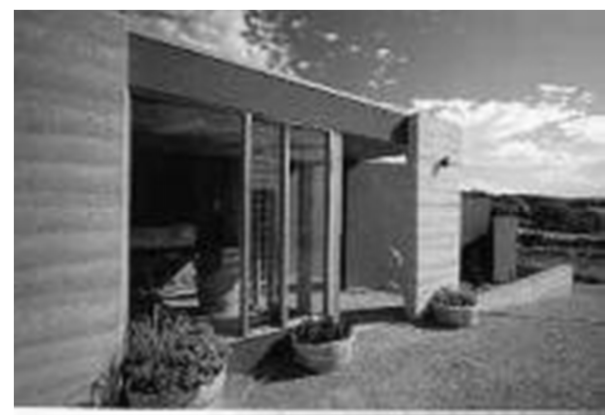

Fig. 7. The design of the sand pressed Rammed Earth

\subsection{Compressed sand and tires rammed Earth and tires}

It has illustrated in Fig. 8 that the technique by using it as the basis for a system housing Earthship with the same concept of the design technique brick sand. 


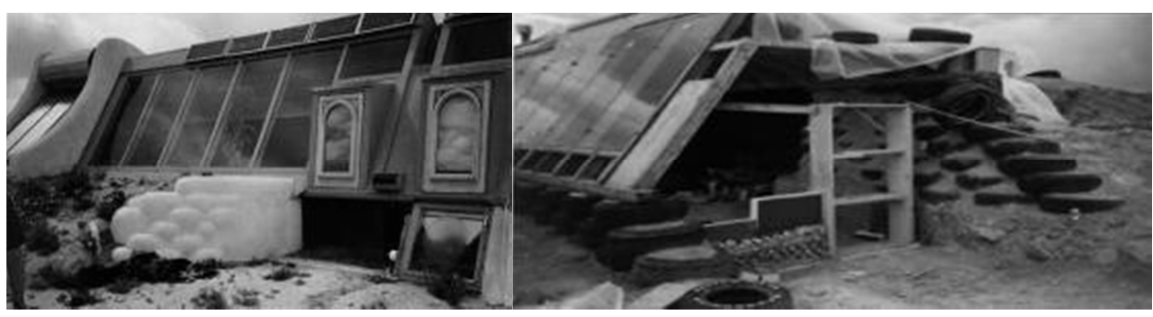

Fig. 8. The use of technology Goalmouths sand and tires

\subsection{Clay brick high-quality super-adobe}

In Fig. 9 this new style newly invented, and is one of the fruit of the architect, 'Nader Khalaly' Institute who works in California thinking although the origins of this method due to the construction methods of the sand used in the Middle East and other construction methods sandbagged created by enthusiasts SoftTec.

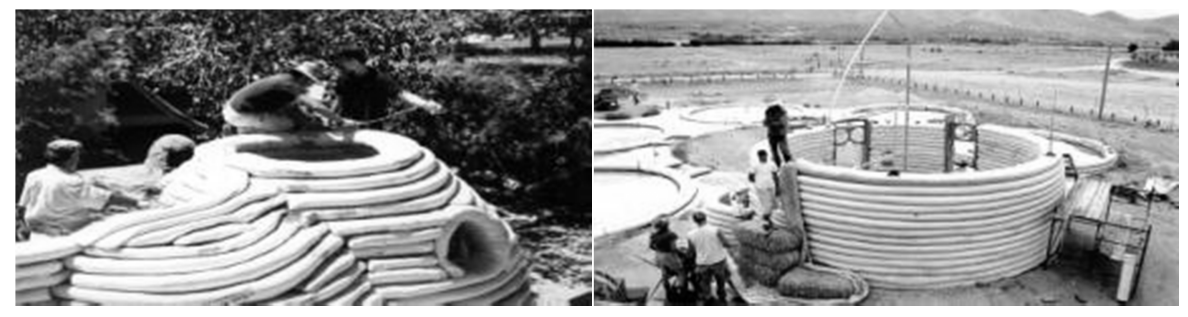

Fig. 9. The construction in the form of pots potter wrapped a method

\subsection{Straw pal Straw Bale}

In Fig. 10 one of the very most famous techniques to green building techniques among supporters, and that in fact Kachteraa modern comparative unique in the United States as a general revolution genius in the nineteenth century.
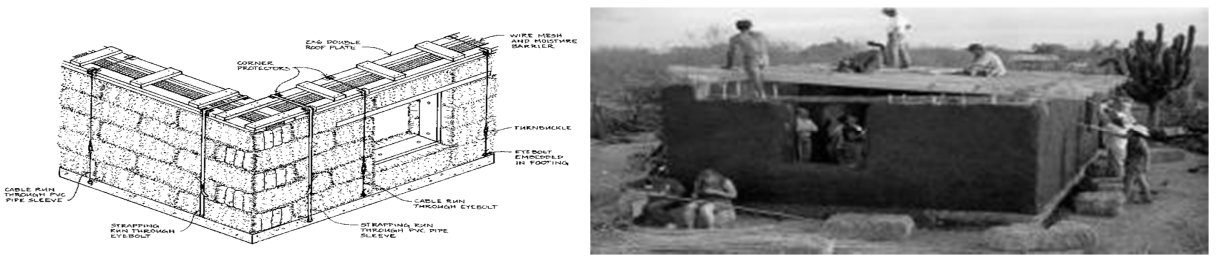

Fig. 10. The construction method using Straw Bale installation method openings and bishop

The walls made of sand can leave without a layer of clay or put them out of this class. The final touches are necessary when using adobe unstable, as he has to be renewed frequently based on the damage caused by the conditions of annual flights. It can lend the finishing touches on the interior walls using a layer of clay, wax or clay mixed with honey; and unfinished buildings are covered with a thick layer of mud 
slurry from home and abroad and are supported plastic network. This is an important activity not only for appearance, but also because the material bags can damage quickly when exposed to UltraViolet (UV) as seen in Fig. 11.

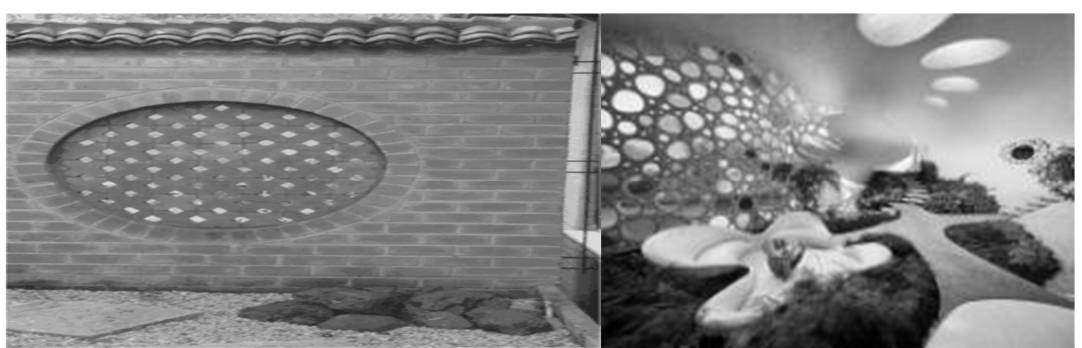

Fig. 11. Sandstone bricks in the building where we see that he can leave the walls made of sand without a layer of clay or put them out of this class

\section{Results}

'Dastan' son 'Khalili' and the daughter of his sister are now implementing the idea and way of life through the arts and architecture dirt Institute, California. In this Institute are organizing workshops in which students do not have the know-how in the field of architecture to build houses of dirt where they learn how to build simple homes include only the most basic materials (soil, water and fire) and the most basic architectural forms (archways, domes and vaults), as part of a seminar spread over two days. And where the implementation of many of the designs from the beginning of exotic exquisite designs in which basements were made of mud brick, [7] and the end of minimalist design with domed buildings bags of sand, [8].

Extent of application determinants environmental sandy architecture in Egypt is respectively portioned as design using elements of nature, the use of architectural techniques to achieve this integration, and use of information technology.

1. The elements of nature include Sand, the sun, water, and wind. There are 1) sand: Desert ratio in Egypt 84\% which makes Egypt the first countries in the world in the desert has space; 2) the sun: Egypt has the highest brightness of the sun in the world, including more than three thousand hours a year, and income from solar energy rate of $\$ 6 /$ kilowatt hours per square meter per day on average throughout the year and the average of the different climatic zones in Egypt. The sun can be converted into electricity; 3 ) water: it can overcome this problem through the use of modern farming techniques and the exploitation of groundwater sources, including nuclear technology provided by the possibilities, as well as the provision of water from seawater analysis in coastal areas, through solar energy in the event of their development; 4) the wind: Wind Atlas Egypt scientifically accurate confirms the existence of sources of wind energy can be exploited (there are areas characterized by high wind speeds in the Eastern or Western Sahara); 
2. The use of architectural techniques includes internal courtyard, contracts, domes, and Roof Garden;

3. Use of information technology comprise of electrical appliances and sensors.

From the previous scheme, it finds that 'environmental sandy architecture projects' can contribute to Fig. 12 improvement of Egypt's economy through its contribution to the establishment of many of the other support projects including:

- Reconstruction projects: reconstruction desert in Egypt and establishment new cities with very little cost;

- Industrial projects: - Establishment of desalination of sea water and groundwater stations (the coast of Western Sahara is a natural extension of Egypt's future);

- Take advantage of intensity of the wind speed and the percentage of the sun's brightness in clean electric power production and to establish integrated and self-sufficient urban communities.

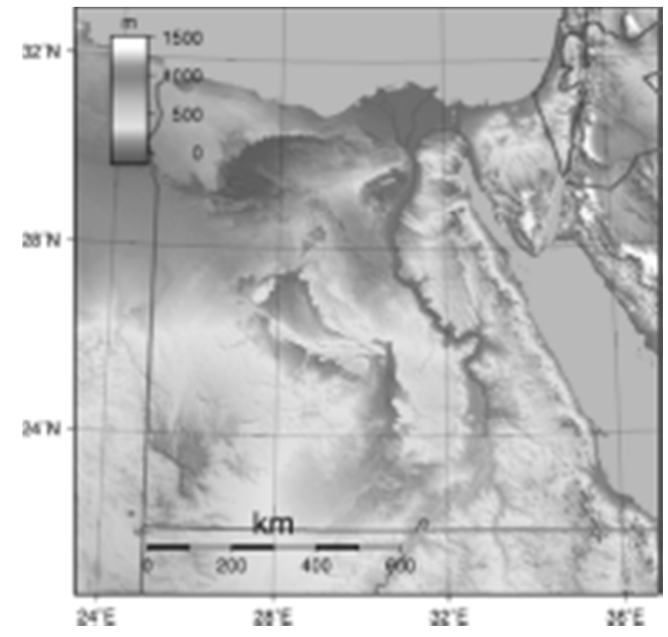

Fig. 12. Map of Egypt

- Take advantage of the sun's brightness ratio in clean electric power production where the air quality in the Egyptian deserts and lack of humidity increases the efficiency of utilization of solar energy (Fig. 13);

- Mining projects: variety;

- Agricultural projects: the trend to agriculture by raising community awareness of the culture of the desert to live with the desert environment and adapted it for sustainable development, where the different farming methods and the type of crops in desert areas for the Valley and Delta, which requires rehabilitation of agricultural, the use of experts in all fields for the rehabilitation of the human elements coexistence with the desert and adaptation of science and technology to achieve this goal;

- Tourism projects: Variety. 


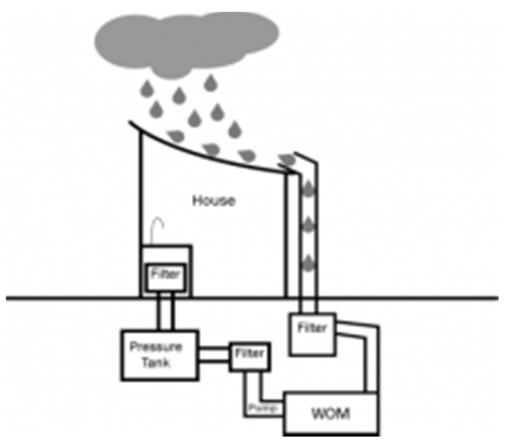

Fig. 13. All integrated systems in the minivans of rainwater and solar panels to collect energy reflector tanks

\section{Discussion}

The environmental sandy design aimed to achieve high system between the building and its vital surroundings so as achieve the integration with the environment. Besides, the paper has some important values as follows:

- Building sand environmental is building, which integrates with all that surrounds him and interacts with him unresponsive environmental requirements and the humanitarian and design based on zero-time materials (earth, water, air, and fire), through the use of modern technologies with reviving old models of traditional architectural techniques [9], [10].

- In implementation of the architecture made of sand are integrated primary elements (earth, water, fire) with the most famous architectural elements (Pointed contracts and domes);

- The internal vacuum for environmental sandy architecture is a cosmic no timetable vacuum combines between romance and rationality - Romantic, where integrates with all that surrounds him and interact with him unresponsive to environmental and humanitarian requirements and design with reviving the old models of traditional architectural technology, Rational by integrating modern technology and information technology;

- It might integrate an application on information technology for the trends in rainfall measures and the number of substantial rain events with continually rainfall quantities. A solar-powered electronic rainwater collector was extended with the emphasis on its remaining small-size, incompetent, and inexpensive for practice against wet dethronement monitoring network in environmental sandy architecture [11], [12].

- Architecture sandy environmental provide environmental solution for reconstruction after disasters that occur in infrastructure and human shelters where it is necessary and urgent to build a very self-help organization and emergency shelters; 
- Considerations of energy conservation and rationalization of consumption remain one of the key points that outweigh the environmental sandy buildings for its rationalization in the field of energy;

- Technology of environmental sandy architecture is new where it integrated and consistent formally and functionally with different environments and models, but according to the ruling concept in every age;

- There is a strong complementarity between information technology and construction technology as one of the factors affecting the formation of the features in the twenty-first century building (building the future);

- Environmental vacuum sand (as a kind of intelligent vacuum) is based on two pillars, namely:

- First, determine the basic standards for the environment, which provides a wide range to choose the way of integration with the environment (natural elements, architectural styles) and thus gives the opportunity to apply to the real ideas of the designers on the ground;

- Second, multiple computer programs that make the actual applications of the theoretical ideas more easily and more cost-efficient than ever before.

\section{Conclusions}

It is important to state intervention models of these environmental sandy buildings within large national projects and state-sponsored institutions, but the right concept and developed it. Some conclusions are drawn as:

- The formation of an integrated research team covering all disciplines related to environmental sandy architecture (severe, information technology) to carry out a series of research and specialized studies to examine the possibilities and ways of technology 'Environmental sandy architecture' application in the contemporary domestic and extent of integration reality with the internal vacuum and prosecution all that is new in the intellectual revolutions and modern architectural schools;

- Interior designer must be familiarity with and design patterns foundations of environmental and identify successful experiences and global applications where it is located upon him the responsibility to reach sandy ecological design solutions to suit the nature of reality Egyptian architect contemporary sake of preserving the environment;

- Architect and interior designer must contact with modern science, systems and techniques and remains interactive and integrated to accommodate the potential of new technologies;

- Promote the exchange of information and experiences between universities in regard to the progress in the 'environmental sandy architecture' both on the scientific and academic process level or specialized student activities based on innovation in the composition of the internal design of the vacuum techniques;

- Open scientific disciplines fit in with the sand needs of the environment, especially in the field of renewable energies where it is necessary to use this 
clean energy (sand exploitation in solar panels industry as containing 'silicon' component, which is the primary ingredient in solar panels industry) to protect future generations next.

\section{References}

[1] Zhao D., Bachmann B., Wang T. Architecture and landscape design for Beikanzi Village in China: An investigation of human settlement and environment, Pollack Periodica, Vol. 13, No. 2, 2018, pp. 231-236.

[2] Ravina D. V., Shih R. R. L., Medvegy G. Community architecture: The use of participatory design in the development of a community housing project in the Philippines, Pollack Periodica, Vol. 13, No. 2, 2018, pp. 207-218.

[3] Anna Józsa. The beginnings of public theatre architecture in Hungary in the age of enlightenment, Pollack Periodica, Vol. 8, No. 1, 2013, pp. 109-122.

[4] Marczak L. B., Thompson R. M., Richardson J. S. Meta-analysis: Trophic level, habitat, and productivity shape the food web effects of resource subsidies, Ecology, Vol. 88, 2007, pp. $140-148$.

[5] Defeo O., McLachlan A. Patterns, processes and regulatory mechanisms in sandy beach macrofauna: a multi-scale analysis, Mar Ecol Prog Ser. Vol. 295, 2005, pp. 1-20.

[6] van der Zee E. M., van der Heide T., Donadi S., Eklof J. S., Eriksson B. K., Olff H., van der Veer H. W., Piersma T. Spatially extended habitat modification by inter tidal reef building bivalves has implications for consumer-resource interactions, Ecosystems, Vol. 15, 2012, pp. 664-73.

[7] Kanjumbaf F., Njuguna A. G., Achoki G. Economic factors influence on funding of the supply-side of housing in Kenya: case study Nairobi, Int. J. Bus. Manag, Vol. 11, No. 10, 2016, pp. 194-205.

[8] Oyelami C. A., Van Rooy J. L. A review of the use of lateritic soils in the construction/development of sustainable housing in Africa: a geological perspective, $J$. Afr. Earth Sci, Vol. 1119, 2016, pp. 226-237.

[9] Nushi V., Jashari-Kajtazi T. The use of specific principles and guidelines for effective and efficient restoration of cultural heritage buildings; case study Jashar Pasha Mosque in Prishtina, Pollack Periodica, Vol. 13, No. 2, 2018, pp. 219-229.

[10] Morais E. J., Vigh L. G., Krähling J. A methodology for the development of historical building archetypes for seismic performance assessment, Pollack Periodica, Vol. 13, No. 1, 2018, pp. 203-215.

[11] Funakura, T., Okochi, H., Nagoya, T., Inazu, K., Minami, Y., Igarashi, Y. Development of solar-powered rainwater collector and observation of wet deposition fluxes on the mountainside of Mt. Fuji, Bunseki Kagaku, Vol. 56, No. 9, 2007, pp. 805-811.

[12] Kawasaki A., Meguro K. A preliminary investigation on the introduction of housing water tanks to store rainwater for improving urban environment and disaster risk reduction, Mon. J. Inst. Ind. Sci, Univ. Tokyo, Vol. 63, 2011, pp. 451-456. 